Lingua e Literatura, $\mathrm{n}^{\circ} 24$, p. 169-174, 1998.

BRUNER, Jérôme. L'éducation, entrée dans la culture. Les problèmes de l'école à la lumière de la psychologie culturelle. Paris, Retz, 1996.

\title{
A PSICOLOGIA CULTURAL: UM CAMINHO PARA A ENTRADA DA EDUCAÇÃO NA CULTURA?
}

\section{Lélia Erbolato Melo*}

"Não se pode compreender o homem sem levar em conta a cultura na qual ele está inserido" (Jérôme Bruner).

A intenção deste trabalho é revisitar uma obra recente (1996) de Jérôme Bruner em que ele preconiza o desenvolvimento de uma psicologia cognitiva orientada culturalmente. Neste sentido, o erro do behaviorismo, segundo o autor, era de se interessar apenas pelos comportamentos, enquanto o erro das ciências cognitivas é de se interessar pelos processos mentais, mas sem levar em conta a cultura na qual o individuo está inserido. Embora, no início, Bruner fosse um psicólogo estritamente experimentalista trabalhando sobre a percepção, ele sempre pensou que é ridículo tentar compreender o homem sem levar em conta o ambiente cultural no qual e pelo qual ele opera no mundo. Para tanto, preconiza o desenvolvimento de uma psicologia orientada culturalmente. Afinal, em que consiste uma tal visāo da psicologia? O postulado central desta abordagem é que o espírito se constitui através da cultura. A

(*) Professora do Departamento de Lingüística, FFLCH-USP. 

Melo.

significação que cada um de nós tem do mundo e de si mesmo é modelada pela cultura e depende da existência prévia de um sistema simbólico partilhado pelos membros de uma comunidade. É, pois, essencial estudar como este sistema de valores, de trocas e de poderes que constitui uma cultura influi nas pessoas que fazem parte dela. Por outro lado, é impossivel compreender a atividade mental se nāo se considera o contexto cultural e os meios que ele propõe, enfim, os mil detalhes que dão ao espírito sua forma e importância. Aprender, lembrar-se, falar, imaginar: tudo isto é possivel porque participamos de uma cultura.

A vida mental é vivida com os outros, é moldada no objetivo de ser comunicada, e se manifesta graças a códigos culturais, tradições... Isto nos leva além dos muros da escola. A educação não se realiza somente nas escolas, mas também na "mesa familial" quando todos os membros da familia se esforçam por encontrar um sentido que lhes seja comum no que aconteceu durante o dia, ou quando as crianças procuram se ajudar mutuamente para dar um sentido ao mundo dos adultos, ou ainda quando o professor e o aprendiz trocam idéias sobre seu trabalho. Nada melhor do que as práticas educativas para testar a validade de uma psicologia cultural.

A obra em questão foi escrita ao longo de uma pesquisa que ele desenvolve em colaboração com sua esposa e colega, Carol Fleisher Feldman, pesquisa cujo tema era precisamente a "narrativa" enquanto modo de pensamento, mas também enquanto expressāo da maneira pela qual uma cultura considera o mundo. Para Bruner é através de nossas narrativas que construímos uma concepção do que somos no universo, e é através das narrativas que uma cultura fornece a seus membros modelos de identidade e de ação. O lugar central que ocupam as narrativas não resulta de uma disciplina única; está na confluência de várias disciplinas: literatura, sócio-antropologia, lingüistica, história, psicologia e informática. Bruner confessa que aca- 
bou por considerar esta confluência como um dado fundamental tanto no estudo que desenvolve sobre narrativas como nos estudos consagrados à educação.

Algumas questōes a esse respeito poderiam ser colocadas. Todos estes novos trabalhos, toda esta mobilização desde a revoluçāo cognitiva permitiram pelo menos melhorar a educação das crianças vítimas dos grandes flagelos que são a miséria, a discriminação e a alienação? Tivemos êxito em isolar caminhos promissores que nos permitiriam organizar a cultura da escola de maneira a ajudar as crianças e recomeçar? O que é preciso para colocar em funcionamento uma cultura escolar verdadeiramente eficaz, que forneça aos jovens os meios de apoderar-se de todos os recursos e de todas as oportunidades que oferece a cultura na qual eles evoluem?

É evidente que não existe uma resposta totalmente satisfatória a estas questōes. Mas os indices que nos encorajam a prosseguir não faltam, como lembra Bruner. Uma das experiências mais promissoras pode ser observada nas escolas que tomaram como modelo uma "cultura da aprendizagem mútua"

Estas classes são o modelo do que se poderia introduzir se nossa cultura decidisse enfim se consagrar plenamente à educação, reconciliando as noçōes de prazer e eficiência. Desenvolve-se, então, uma partilha mútua, uma divisāo do trabalho e uma troca dos papéis, e também das ocasiōes de refletir sobre as atividades do grupo. Isto nāo é senão uma das versōes possíveis da "educação ideal" A escola, neste exemplo, é concebida ao mesmo tempo como o lugar de exercicio e de despertar da consciência quanto às possibilidades de atividade mental comum, e como um meio de adquirir conhecimentos e competências. O professor é aquele que, primus inter pares, permite que isto aconteça. Mas esta é uma das possibilidades atestadas a partir de experiências múltiplas já realizadas, e existem ainda outras. 
172 BRUNER, Jèrôme. L' éducation, entrée dans la culture, por Lélia Erbolato Melo.

Prosseguindo em suas reflexões, Bruner admite que há quatro modelos do espírito humano que condicionam quatro formas de pedagogia. Cada um deles valoriza objetivos educativos diferentes. Estes modelos não somente concepçōes do espírito que determinam como devemos ensinar e "educar" mas são concepçōes das relaçōes entre o espírito e a cultura. Procurarei examinar com base no texto de Bruner cada uma dessas representaçōes concorrentes do desenvolvimento humano com o objetivo de avaliar sua implicaçāo no ensino e na aprendizagem.

\section{A aquisição do "saber-fazer" Uma primeira con-} cepção considera que a criança aprende por imitação, olhando um adulto ou um jovem mais experimentado agir. A educação pretende, então, que ele adquira o saber-fazer ("savoir-faire").

Neste sentido, quando um adulto faz a uma criança a demonstração de uma ação que requer uma competência, esta demonstração baseia-se implicitamente na crença de que o adulto tem de que, (a) a criança não sabe como fazer, e (b) de que a criança pode aprender como fazer se lhe mostramos. O ato de mostrar pressupōe igualmente que (c) a criança quer fazê-lo, e (d) que ela talvez esteja tentando fazê-lo. Para aprender por imitação, a criança deve reconhecer os fins buscados pelo adulto, os meios utilizados para atingi-los e o fato de que a ação demonstrada lhe permitirá ter êxito para atingir estes fins.

2. A aquisição de um saber declarativo. Pode-se igualmente achar que a aprendizagem consiste em adquirir um saber formal, presente em livros e na cabeça do professor. Estes conhecimentos se apresentam sob forma de proposiçōes e regras que devem ser aprendidas, memorizadas, depois aplicadas. É a concepção mais corrente da educação. O ensino didático é, em geral, baseado na convicção de que os alunos devem ser confrontados aos fatos, princí- 
pios e às regras da ação que devem ser aprendidos, memorizados, depois, aplicados. Ensinar deste modo é estar convencido de que o aprendiz "não sabe tal ou tal coisa" que ele é ignorante ou inocente em relação a certos fatos, certas regras ou principios que podem lhes ser fornecidos. $O$ que deve ser aprendido pelo aluno é concebido como se encontrando "no" espirito do professor tanto quanto em livros, mapas, etc. O saber consiste simplesmente em "procurar" ou em "escutar"

\section{O desenvolvimento da troca intersubjetiva. A úl-} tima tendência de pesquisa sobre "o espírito do outro" já evocada é a manifestação de uma corrente atual mais vasta que visa reconhecer o ponto de vista da criança no processo educativo. Segundo esta abordagem, o professor procura compreender o que pensa a criança e como ela chega a uma conclusão, em que ela crê. As crianças, como os adultos, são consideradas como individuos que constroem um modelo do mundo para chegar a analisar sua experiência. A pedagogia existe para ajudar a criança a melhor compreender, mais profundamente, menos unilateralmente. Enriquece-se a compreensão pela discussão e cooperação, e a criança é encorajada a exprimir suas próprias intençōes a fim de melhor promover o encontro de seu espírito com o do outro, que pode ter outros pontos de vista.

Uma tal pedagogia baseada na troca mútua repousa no pressuposto segundo o qual todos os espiritos humanos sāo capazes de professar crenças e idéias que, graças à discussão e à interação, podem evoluir para um certo quadro de referência pontilhado. A criança e o adulto têm pontos de vista diferentes, e cada um é encorajado a reconhecer o outro, mesmo que nāo concorde com ele.

4. A gestāo do saber "objetivo" Esta quarta perspectiva considera que o ensino deveria ajudar as crianças a perceberem a diferença entre, de um lado, o que é saber 
174 BRUNER. Jéróme. L'éducation, entrée dans la culture, por Lélia Erbolato Melo.

pessoal e, de outro, "o que se deve saber" segundo a cultura. Mas elas nāo devem somente perceber esta distinção, elas devem igualmente compreender o princípio na história do saber. Como podemos incorporar uma tal perspectiva em nossa pedagogia? Em outros termos, o que ganharam as crianças quando começam a distinguir o que é conhecido canonicamente e o que elas conhecem pessoalmente?

$\mathrm{Na}$ opiniāo de Bruner, o professor deveria usar alternadamente estes quatro modelos, segundo as circunstâncias e os temas abordados.

Finalmente, como fecho, o autor lamenta que se tenha desenvolvido muito a aprendizagem formal em detrimento de outros tipos (de aprendizagem); observa também que se abandonou nas escolas as artes de narraçāo, como o canto, a ficção e o teatro. O que significa eliminar um aspecto muito importante da vida da pessoa, pois existe no ser humano uma predisposição para organizar o vivido sob forma de narrativa, construindo intrigas. 